Smith, P.A. $\neq$ Mound, S. *, Brown, N. †, Leonard, R. *, Lovell, C. *, Horrocks, E. $\neq$, Bennett, $S . \neq$

* Hampshire Constabulary + Nottingham Trent University $\$$ University of Portsmouth

\title{
Empirical Approaches to Improving the use of DNA in Crime Scene Investigative Practice
}

\begin{abstract}
This paper reports on a collaborative project which explored the targeted use of swabbing evidence sources which, up until now, have not been routinely recovered or utilised for DNA analysis. All genres of the forensic portfolio have undergone significant changes driven by economic, political and technological influencers which have resulted in an array of interpretations on its frontline delivery often based on local requirements. The approach reported in this paper pertains to a research project bringing together a collaborative team of researchers, representing practitioners and academics, working in conjunction with the forensic service providers. The project reviewed the process of swabbing glove marks at crime scenes comparing methods used to the DNA profiling outcomes. The findings showed a significant improvement in DNA outcomes from the swabbing of glove marks and provided key data to guide practice and crime scene methods to meet new operational requirements.
\end{abstract}

KEYWORDS: Forensic Science, DNA, Crime Scene Investigation

\section{Introduction}

The examination of items for the presence of "trace DNA" (Gill, 2013) is by no means a new venture (Wickenheiser, 2002; van Oorschot, 1997). With increasing sensitivities of the profiling methods opportunities to exploit these benefits from the crime scene perspective have become more abundant and offer increasing evidence potential if recovered, managed and processed appropriately. This paper reports on a collaborative project which explored the targeted use of DNA swabbing of evidence sources which, up until now, have not been routinely recovered or utilised for DNA analysis. The collaboration, between operational Crime Scene Investigators (CSI) and academia, designed the research to empirically measure and record the relative impact of the swabbing of glove marks found at crime scenes in relation to the DNA outcomes.

The project heralds a renewed endeavour in researching novel crime scene methods which, it is fair to say, have remained relatively unchanged for a number of years despite many advancements in the associated science and technologies. The discipline deploys an amalgamation of scene recording methods, principally photography and 
written documentation, forensic recovery of trace, biological and related evidence along with the visualisation, capture and recovery of marks and impression evidence. These remain as core functions despite a plethora of changes to forensic service provision, science and technology, and accountability.

The purpose of the current study is to fully harness the benefits afforded through the new sensitivities and capabilities of DNA 17. The point of departure relating to the processing of DNA material from the scene is the requirement for a reciprocal progression in scene techniques to ensure new profiling capabilities and subsequent potential are realised operationally for police investigations. Essentially, developments such as DNA 17 cannot be implemented in isolation, associated practices need to be reviewed to maximise the benefits available (Smith et al., 2007; Ribaux \& Talbot-Wright, 2014).

The principal crime scene method reported here involved the swabbing of glove marks observed at scenes and submission of the swabs for analysis using DNA 17. However, the research methodology is not isolated to the processes and outcome, it is also concerned with developing CSI actions at the scene to improve the effectiveness of the CSI processes, for example, what they record and the impact of other scene methods on the quality of DNA samples recovered. The aim is to align process and task change, monitor benefits and implement structured and tested improvements at the behest of the external demands or requirements, in this instance more sensitive DNA profiling techniques, in an empirical way. The outcome identified improved outcomes from swabbing glove marks, but also allowed the iterative review of the processes and techniques directing the tasks undertaken by the CSI when recovering swabs of potential DNA sources from the crime scene.

To fully review the relative 'success' of the new approach and to help embed new methods into practice, there were a series of parameters put in place to ensure the appropriate data, in regards to the CSI examination, was recorded and utilised appropriately. This involved the CSIs compiling a detailed log of actions, findings and resources used at the crime scene including the recording of the surface, where marks were recovered from, the powder or enhancement technique used, the method of lifting, etc. (this is explained in more detail below). The method adopted was designed to utilise the data to measure techniques and scene parameters against outcomes generating reproducible inferential data to be used with further qualitative work to guide future practice. 
We report on the methods and outcome, and highlight the case outcomes in the discussion to demonstrate the impact of using the methods. The findings are the first stage in reporting the research outcomes and will be further consolidated by control studies and associated qualitative work which will be reported on in the near future. Furthermore, it is anticipated that the initial model presented could be extrapolated to a broader array of scenes and inform the broader use of forensic enabled intelligence utilised to maximise the DNA evidence potential from a more diverse range of crime scene circumstances.

\section{Materials and Methods}

Between September 2014 and December 2014, during their day to day operations, CSIs were asked to swab any glove marks which were observed during their examinations. The double swab method (wet and dry) was used (Pang \& Chung, 2007) on the glove marks at the point where the CSI observed the mark. This was either at the initial observation with an appropriate light source or after the marks had been developed using the selected powder. To achieve the aims of the study the CSIs were asked to record the variables relevant to the recovery of any DNA present on the swabs, this included:

- The type of crime: including burglary to dwelling, burglaries other than dwelling and serious / major crimes.

- The enhancement method: Some marks were unenhanced and swabbed on discovery, others were powdered and the latent marks swabbed after enhancement. The CSIs were requested to document the powder used.

- Pattern code, defining the material type observed: CSIs were asked to record the material observed, for example textile glove mark patterns or latex, rubber gloves, etc.

- Location of the glove mark and the material it was located on: CSIs noted whether the marks were found on windows, doors and / or artefacts located in the scene and noted the type of material, for example glass, painted wood, etc.

- Background swabs taken from the location and whether volunteer DNA swabs (an elimination sample taken from those having legitimate access to the premises) were taken from the aggrieved: CSIs noted where background controls were taken and whether they were in possession of volunteer DNA samples. 
This data was logged on the crime scene report form and inputted into the crime records system and into the crime scene data management system. The swabs were submitted for analysis in the conventional manner to the forensic service provider, in this instance Key Forensic Services Ltd. The swabs were profiled using DNA-17 profiling standard and the outcomes were recorded both in regards to the type of profile achieved and whether the profile outcome resulted in identification and subsequent detection.

At the culmination of the four month period 659 glove mark swabs were recovered from 525 crime scenes. Each of the data records were logged by the CSI onto the crime scene data management system corresponding to the 525 crime scenes. The data selected and corresponding variables were recorded and these can be seen in Table 1. 
Table 1: Variables recorded by the CSIs, including number and type recorded.

\begin{tabular}{ll}
\hline Type of Variable & Number recorded \\
\hline Crime Types & 398 \\
Burglary to Dwelling & 206 \\
Other Burglary & 10 \\
Aggravated Burglary & 17 \\
Theft from a motor vehicle & 12 \\
Theft of a motor vehicle (incl. TWOC) & 6 \\
Theft inc. Handling Stolen Goods & 6 \\
Robbery & 2 \\
Criminal Damage & 2 \\
Other & \\
Location of Marks (most common) & 193 \\
Window & 77 \\
Door & 59 \\
Box & 34 \\
Jewelry Box & 24 \\
Electronic Device & 19 \\
Drawers & 23 \\
Vehicle Related & 22 \\
Cupboard & 12 \\
Safe & 11 \\
Metal & 10 \\
Kitchen/Bathroom & 8 \\
Till & \\
Enhancement & 190 \\
Magneta Flake & 37 \\
Aluminium Powder & 6 \\
Black Powder & 4 \\
Bichromatic Powder & 171 \\
And, no enhancement & \\
Glove Pattern & 9 \\
Total number of Unique CSI & 41 \\
\hline
\end{tabular}

\section{Results \& Discussion}

Principally, the data was recorded to first establish whether the swabbing of glove marks increased opportunities to detect crime through the recovery of DNA from glove marks. As a secondary aim, variables were evaluated to ascertain whether there was any significant relationship between the outcome and a specific powder, surface or glove mark.

Of the 659 swabs recovered, 588 (89.2\%) contained some level of DNA, including partial, 'more than one' and full profiles. Forty-four (6.6\%) of these were suitable to search against the National DNA Database and 18 (2.7\%) resulted in an identification and, currently, six resulted in a detection, the details of four of these are outlined below. Twenty-four (3.6\%) were also suitable for speculative searching on the NDNAD, with 13 
$(2.0 \%)$ of those providing a potential match for intelligence purposes only (this is where a crime scene mark has matched against an individual's DNA profile on the database, if subsequently detained for the crime then an evidential DNA sample is required). Over ninety-three percent of the marks were recovered from burglaries (60.4\% were found at burglary to dwellings, $31.3 \%$ at 'other' burglaries, and $1.5 \%$ at aggravated burglaries). The other $7 \%$ of the glove mark swabs were recovered at various other crime types including theft and robberies.

The most common area where glove marks were found was at the Point Of Entry, including windows (29.3\%) or doors $(11.7 \%)$. Other locations included boxes, drawers, safes, cases, jewellery boxes, vehicles, money boxes and on electronic devices. Background controls were taken for just $43.7 \%$ of the marks, this is because background controls are not routinely taken; it is often now done at the discretion of the CSI. Volunteer DNA was taken in $12.4 \%$ of cases. CSIs were also asked to record the pattern code, it is worthy of note that there was no significant relationship between the type of pattern found and the recovery or identification of DNA material. Forty eight percent of the marks were not given a pattern code, but this may be due to some of the marks being smudged. The most common pattern found was 'Fabric' $(24.9 \%)$. In relation to using fingerprint powder, in $30 \%$ of cases it was not stated whether a powder was used or not. In the recorded cases, Magneta Flake was used most commonly $(29.7 \%)$ to enhance glove marks, followed by the swabbing of unenhanced marks $(25.9 \%)$.

Each variable was recorded and coded for statistical analysis. This was undertaken to verify the frequencies relating to the scene and procedures used (presented above) and any relationship between the variables and outcome in regards to the result obtained:
1. No DNA present
$(\mathrm{n}=71)$
2. Partial profile
(n= 291)
3. More than one profile
( $\mathrm{n}=\mathbf{2 8 4})$
4. Full profile
$(\mathrm{n}=\mathbf{1 3})$

The type of DNA profile was coded as above and this was analysed in relation to the variables to establish whether there was a relationship, for example, whether the profile outcome differed in accordance with the types of enhancement used, whether it differed between the types of glove marks encountered, and so on.

Initial results revealed that there was a significant association between the development method and producing a DNA profile $(18, \mathrm{~N}=659)=43.73, p<0.01)$. This was particularly prevalent when comparing the swabbing of unenhanced marks with the other prevalent enhancement method used, which was Magneta Flake. Marks were 
swabbed 171 times from unenhanced marks and a DNA profile was not achieved in 13 (7.6\%) cases, Marks developed using Magneta Flake were swabbed 190 times and produced no DNA profile in 27 (14.2\%) cases. It is worthy of note that in 196 cases no data was recorded by the CSI, though this has been included in the statistical analysis, this is a significant issue for any interpretation and for the research in general, hence the need for further control studies, which is discussed later.

To investigate this further, a Kruskal Wallis test was conducted to compare the effect of physical development on the DNA profile. This analysis revealed that there was a significant effect of the type of physical enhancement on the resulting DNA profile $[H(6)=34.08, p<.001]$. The unenhanced marks provided better outcomes in terms of gaining a partial or full profile when compared to the powdered marks. When comparing the results for unenhanced and powdered marks there is difference between the mean rank scores for the level of profile recovered (higher scores reflect better DNA profile outcomes; see Figure 1 below). Further corroboration is needed with the same variables being tested under controlled conditions for this to be taken further, this is being undertaken in future studies.

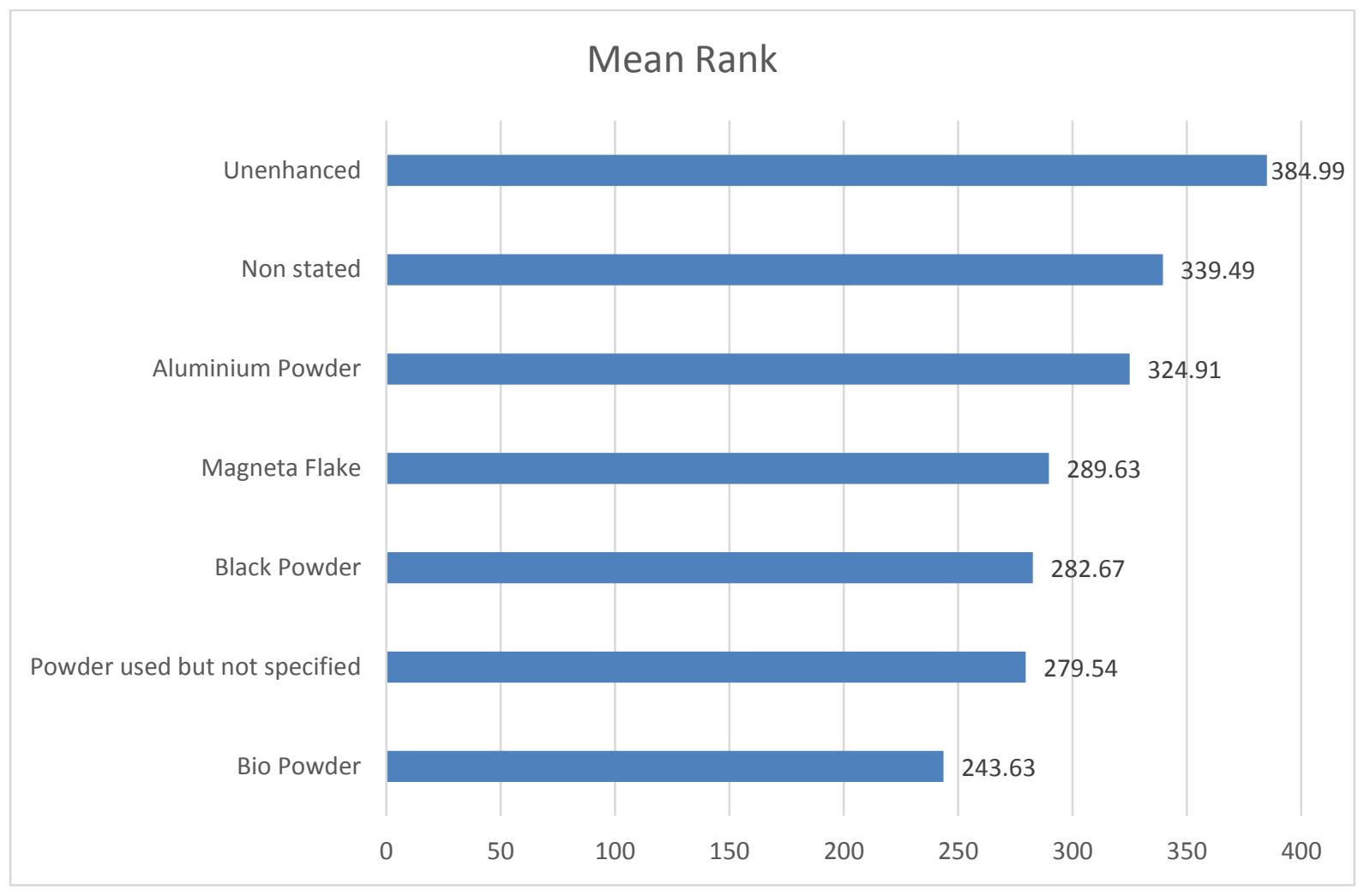

Figure 1: Mean Rank scores for Profile score by type of Physical Development (From Kruskal Wallis analysis). 
Marks that are smudged, distorted or otherwise lacking adequate detail may not be useful for conventional pattern comparison but can still be used as a possible DNA source in forensic investigations (Oleiwi et al., 2015). However, if the outcome of the DNA analysis showing improved results when the glove marks are unenhanced, the findings from the ANOVA could suggest the need to encourage more defined and effective use of light sources and non-invasive methods to detect the glove marks before any enhancement is used. In fact, the significant differences between CSIs recovery and successes have propagated further qualitative research to investigate where the inconsistencies are, their operational significance and where this needs to be rectified. The findings suggest that though the results and outcomes are encouraging, further work is required to bring consistency across CSI practice. As stated, further consolidating data is needed, but the apparent differences, notwithstanding the difference between enhancement methods and establishing 'what works' based on empirical evidence, is being incorporated to educate and develop the methods used.

These observations were, and continue to be, important in the move towards further competency testing and implementation of ISO17025 and ISO17020. The application of methods outlined through this research were undertaken in an accredited laboratory, and were done commensurately with the implementation of the accreditation processes used to propagate and encourage improvements in professional skills. This has demonstrated the need to be particularly vigilant in regards to contamination and the abounded risks linked to new, more sensitive DNA profiling techniques (Gill, 2014). Subsequently, the research outcomes are being used iteratively to improve standards and to empirically assess the value and benefit of new methods, essentially using evidence to ratify and verify process changes.

Associated qualitative work has been undertaken which looked more in-depth at the outcomes and the case specifics relating to the identification and subsequent detections. As stated, there have been, thus far, six detections associated to the recovery of DNA from glove marks found at the scene from this study, some have resulted in significant sentences and relate to serious crime and persistent offenders.

This demonstrates the impact the method has had on positive criminal justice outcomes. Comparative studies from other police areas will also provide a more informative picture and further research projects are required to define the way in which the variables used in the CSI process inhibit DNA recovery from glove marks, it will help establish optimum surfaces of items and glove type for secondary transfer of DNA, and whether the results improve with better eliminations and controls. Therefore, further work is being done to consolidate the findings 
and improve the providence of the outcomes to fully measure the impact on operational practice. The key technology enabling these practice improvements is forensic DNA profiling where the sensitivities of the profiling science and capability of related technology has brought a level of enhanced potential requiring empirical review. This is by no means a new quandary, but certainly, as highlighted by Guiness (2015) and others (Gill, 2014; Goray, 2012; Lowe et al; Oorschot et al (2014) ; Ladd et al) the implications and likelihood has grown in accord with the profiling sensitivities. Therefore, the recovery of DNA from glove marks needs to be considerate of the contamination risk and innocent deposition of material containing DNA.

The contamination risks have been clearly identified and are no more apparent in a practical sense than when linked to the Adam Scott and Farah Jama cases, reported on by the forensic regulator (Guiness, 2015; FSR, 2012; the Age, 2009). The causes of the contamination in these cases cannot be ascribed to DNA 17 per se, but they are indicative of the profiling sensitivities and the need for the highest level of scrutiny throughout the process to avoid or reduce the risk of contamination from crime scene to analysis. The point of departure for this paper is the crime scene and associated processes. The swabbing of glove marks and recovery of DNA material brings further issues with contamination and ensuring CSI practice and resources used are commensurate with the sensitivities of profiling and the likelihood of contamination linked to the ubiquity of potential DNA evidence sources.

It is argued that information achievable from any scene investigation needs to be optimised avoiding superfluous evidence and maximising probative value. The nature of CSI work is absorbed in forming and shaping hypothesis based on the morphology of the scene and location of evidence therein. The implicit or explicit use of scientific method by the CSI means they are, or at least should be, continually testing the hypothesis in an iterative review of information as it unfolds, defining the evidence which bears relation and adds probative weight to the investigation (Jamieson, 2001; Crispino, 2008). Often nowadays major changes to crime scene practice attempt implementation without forethought and research to look at the implications of the changes. The approach taken here is developing collaborative and congruent research to prudently forestall the impact of major technological and procedural changes, aligned with the professionalising and embedding of an empirical zeal to the scene investigators skill set (Kelty and Julian, 2012). 
The findings of Ludwig and Fraser (2013) and Kelty and Julian (2012) shows tangible links with the 'art and science' of the investigator posited by Tongue and Bowling (2006). It was therefore disappointing that measurable data was limited due to incomplete notes and recordable fields by some of the CSIs. However, it does demonstrate that the endeavours articulated above need to be associated with further promotion of good scene practice, and the practitioners must be embedded in the research ethos and process recognising the tangible link between operational improvements and implementing methods generated from the outcomes they produce.

Finally, there is a significant disparity between what is collected by the CSI and what is used in court (Ribaux and Talbot-Wright, 2014). Therefore there is a requirement to hone scene practice to search and recover evidence which has the most pertinent probative benefit to the investigation removing the misconception of the CSI role being a mere collection vacuum, collecting evidence with little thought to its usability and usefulness to the investigation. The thesis of this paper is for the empirical review of the CSI process, the recovered materials and the techniques used comparatively with outcomes affording reliable inferences of the best techniques and tools used in relation to the probative outcome. Granted, as Ribaux and Talbot-Wright highlight, we need to consider the broader and associated tasks in this process too. It is not isolated to the scene recovery per se, there needs to be due consideration for the investigative process, and of course, the analytical techniques used. In this regard, enhanced sensitivity of DNA 17 has produced more opportunity for proactive use of the evidence and more forensic enabled intelligence.

The UK Parliamentary Committee (2005) acknowledged that forensic science can offer contributions to intelligence, however, there is evidence to suggest volume crime intelligence offers little to the broader solving of crime and in its reduction (Tonry, 2014; Karn, 2013). However, this should not be taken as prosaically as it is defined here, there are a plethora of reasons why forensic science intelligence, or more precisely intelligence in general from the volume crime investigation is not utilised to its fullest potential, it may be down to supporting infrastructures, having sufficient numbers of agents on hand to process the data, etc. Karn (2013) and Tonry (2014) have commented on the general ineffectiveness of the policing approach to the crime reduction problem. However, the contention here is there has not been an empirical approach to measuring what works with any rigour from the processes, techniques and methods deployed, measured against the outcomes. If this was the case then you would have some rich data to be used inferentially to direct practice to what works, this is 
particularly useful for crime scene and forensic investigations. Ribaux and Talbot-Wirght (2014) make further comment on integrating this inductive reasoning for volume crime with policing practice for intelligence purposes.

\section{Conclusion}

Tilley and Townsley (2009) present a continuum of forensic investigation from report to dispatch, forensic recovery to analysis, culminating in its presentation at court. They observe the continuum offers opportunity for error, inefficiency and inconsistency. Guinness (2015) and Gill (2014) concur, in regard to the risk of contamination. Subsequently, there is a salient requirement embroiled into the crime scene investigation mandate to modernise and develop, assuring accountability and competence and to meet the alternating requirement in the development of associated sciences and technologies. This is not a new concept, various reviews have led to changes in the way forensic science is utilised for investigations and policing (Ramsay, 1987; Touche-Ross, 1987; Audit Commission, 1988;Tilley and Ford, 1997; Barclay et al., 1997; Blakey, 2000; Blakey, 2002; House of Commons Science Select Committee, 2005; House of Commons Science Select Committee, 2013). However, this study has shown that the process of crime scene investigations produces a rich data set that can be used to hone practice.

From one perspective this research appears fairly niche, the implementation and review has had profound effect on associated practice bringing new and reliable findings for serious and major crime investigations and general forensic practice. This has defined the allocation and integration of resources including their treatment and management and has guided future strategies relating to the submissions. This paper reports on the initial studies, further work is ongoing using the method, forging and consolidating the collaboration between academia and practitioners. It will be utilised to measure new methods and opportunities to maximise evidence potential from new sources and to hone the scene investigation activities. It demonstrates the benefits of partnership in an endeavour to identify what works and implement new methods with full awareness of its subsequent impact on practice.

\section{Acknowledgements}

This work is supported by a Faculty of Humanities and Social Sciences capacity building project fund. We are very grateful to Key Forensic Services Ltd. For their continued support and advice. We are grateful to Nottingham Trent University and their Forensic Biology Intern, Miss Natasha Brown. 


\section{References}

Audit Commission (1988) Improving the Performance of the Fingerprint Service. London: HMSO.

Barclay, D. (2009) Using forensic science in major crime investigations. In Fraser, J. and Williams, R. Handbook of Forensic Science. Cullompton; Willlan.

Barclay, D. (1996) Using Forensic Science Effectively. London: ACPO/FSS.

Blakey, D. (2000) Under the Microscope. London: Home Office

Blakey, D. (2002) Under the Microscope Refocused. London: Home Office

Burrows, J. Tarling, R., Mackie, A., Poole, H. and Hodgson, B. (2005) Forensic Science Pathfinder Project: Evaluating Increased Forensic Activity in Two English Police Services. Home Office Online Report 46/05. London: Home Office.

Byford, L. (1982) Report by Sir Lawrence Byford into the police handling of the Yorkshire Ripper case. London: Home Office (Released in June 2006, under the Freedom of Information Act)

Crispino, F. (2008) Nature and place of Crime Scene Management within forensic sciences. Science and Justice. 1, 24-28.

Gill, P. (2014) Misleading DNA Evidence: Reasons for miscarriages of justice. London: Academic Press.

Guinness, J. (2015) Considerations in body fluid attribution. Chartered Society of Forensic Sciences Body Fluid Forum, 30 April, 2015. Birmingham,

House of Commons Science and Technology Committee (2005) Forensic Science on trial, seventh report of sessions, 2004-2005. London: Crown Copyright.

Karn (2013)

Kelty, S. and Julian, R. (2012) The seven key attributes of good crime scene examiners: Brief report. Tasmanian Institute of law enforcement studies.

Ludwig, A. and Fraser, J. (2013) Crime scene examiners and volume crime investigation: and empirical study of perception and practice. International Journal of Police Science Management. 3(2) 53-61

A.A. Oleiwi, et al., The relative DNA-shedding propensity of the palm and finger surfaces, Sci. Justice (2015), http://dx.doi.org/10.1016/j.scijus.2015.04.003

Pang B.C.M., Cheung B.K.K. (2007) Double swab technique for collecting touched evidence. Legal Medicine, 9, 181-184

Ramsay, M. (1987) The Effectiveness of the Forensic Science Service. Home Office Research Study 92. London: Home Office.

Ribaux, O. and Talbot-Wright, B. (2014) Expanding forensic science through forensic intelligence. Science and Justice. 54: 494-501 
Tilley, N. and Townsley, M. (2009) Forensic Science in UK Policing: Strategies, Tactics and Effectiveness. In Fraser, J. and Williams, R. The Handbook of Forensic Sciences. Cullompton: Willan.

Tilley, N. and Ford, A. (1996) Forensic Science and Crime Investigation. Crime Detection and Prevention Series Paper 73. London: Home Office.

Tong, D.S. and Bowling, B., (2006) Art, craft and science of detective work. The police journal, 79(4), 323-330

Tonry (2014)

Touche Ross (1987) Review of Scientific Support for the Police, 3 vols. London: Home Office.

van Oorschot, R.K.H. and Jones, M.K. (1997) DNA fingerprints from fingerprints, Nature 387 (1997)767.

Webb, B, Smith, C, Brock, A and Townsley, M (2005) 'DNA fast tracking', Crime science: New approaches to preventing and detecting crime, Smith, M and Tilley, N (eds.) Crime Science Series, Cullompton: Willan

Wickenheiser, R.K. (2000) Trace DNA: a review, discussion of theory, and application of the transfer of trace quantities of DNA through skin contact, J. Forensic Sci. 47 (3) 442-450. 